\title{
SUZANA TODOROVIĆ
}

\section{OSNOVNA SLOVNICA MILJSKEGA ISTRSKOBENEŠKEGA GOVORA: GLAGOLSKI ČASI IN IZBRANE GLAGOLSKE OBLIKE}

Coвiss: 1.01

HTTPS://DOI.ORG/10.3986/JZ.26.2.05

V prispevku so prikazane glagolske oblike, ki jih govorci miljske istrobeneščine uporabljajo $\mathrm{v}$ vsakodnevni komunikaciji. Za posamezne načine upovedovanja prikazujemo spregatve pomožnih glagolov 'eser 'biti' in $\gamma a^{\prime} v e r$ 'imeti' ter spregatvene vzorce za pravilne glagole s končnicami - $a r$, -er in -ir. Pravila rabe miljskih glagolskih oblik so podobna pravilom, ki jih narekuje italijanska slovnica, izvzemši rabo konjunktiva in pogojnika, predvsem pri tako imenovanem hipotetičnem dogodku.

Ključne besede: miljski narečni govor, istrskobeneško narečje, glagolski časi, glagolske oblike, dialektološka raziskava

\section{A Short Grammar of the Muggia Vernacular: Verb Tenses and Selected Verb Forms}

This article presents the verb forms that speakers of the Muggia Istrian-Venetian dialect use in everyday communication. Presented are the conjugations of the auxiliary verbs 'eser 'be' and ya'ver 'have' for individual forms of verbalization and the conjugation patterns for regular verbs ending in -ar, -er, and -ir. The rules for using the Muggia dialect verb forms are similar to those dictated by Italian grammar, except for the subjunctive and conditional, especially in relation to hypothetical events.

Keywords: Muggia vernacular, Istrian-Venetian dialect, verb tenses, verb forms, dialectological study

\section{$1 \mathrm{UVOD}$}

V italijanskem istrskem mestecu Milje (Muggia) domačini poleg knjižne in standardne italijanščine govorijo tudi istrskobeneško narečje, ki spada v italijansko beneško narečno skupino. Italijanski jezikoslovec Alberto Zamboni (1979: 18-19) je beneščino, ki jo govorijo v Istri, Kvarnerju, Dalmaciji, na robu furlanskega območja in vzdolž obalnega pasu - tj. na območju italijanskih krajev Videm (Udine), Palmanova, Spilimbergo, Codroipo, Gorica (Gorizia), Trst (Trieste), Milje (Muggia) -, uvrstil v skupino kolonialnih beneških govorov (it. veneto coloniale). Jezikoslovec Gianfranco Folena (1968-1970: 331-376) pa je jezik, ki so ga Benečani ob koncu srednjega veka s svojo politično ekspanzijo razširili v omenjenih regijah, označil kot veneziano »de là da mar « 'benečanščina na drugi strani morja'.

Istrskobeneško narečje je bilo do konca druge svetovne vojne glavni sporazumevalni jezik vseh Istranov; domačini slovanskih korenin, ki so sicer v zaledju obalnih mest vselej govorili le narečje slovanskega izvora, so bili večinoma dvojezični, saj je bilo zanje znanje istrobeneščine in tržaške italijanščine ključno pri 
trgovanju z meščanskim prebivalstvom. V mestih, kamor so se odpravljali zelo pogosto, so namreč prodajali kmečke in druge pridelke. Zaradi intenzivnih stikov z Istrani romanskih korenin so še danes v slovanskih istrskih narečjih prisotni številni starejši in mlajši romanizmi. Meščansko (istrskobeneško govoreče) prebivalstvo je bilo večinoma enojezično, njihovo narečje pa je zaradi dominantne vloge več stoletij ohranjalo višji sociolingvistični položaj. Po drugi svetovni vojni, ko je istrska mesta zapustilo devetdeset odstotkov Istranov italijanskega rodu, je istrobeneščina izgubila znatno število svojih govorcev. Danes jo v formalnih in neformalnih govornih položajih v vsakdanji rabi ohranjajo pripadniki italijanske narodne skupnosti. Istrskobeneško govorno območje vključuje mesto Milje, slovenski obalni pas z neposrednim zaledjem ter vzhodno in zahodno obalo hrvaške Istre (Todorović 2019: 86).

Miljčani, ki svojemu današnjemu narečju pravijo muje'żan, sebi pa muje'żani, so pred beneško nadvlado govorili jezik ladinskega tipa (Filipi 1993: 275-284). Podatke o zgodovini Milj in njihovem narečju smo objavili v članku Osnovna slovnica miljskega istrskobeneškega govora: od fonemskega sestava do zaimkov (Todorović 2019b).

Milje so edino italijansko mesto, kjer domačini govorijo istrsko različico italijanskega beneškega narečja; za Trst, ki ne leži na istrskem polotoku, je značilna tržaška italijanščina. 1 Ta se od istrobeneščine razlikuje predvsem po številu prevzetih slovenizmov, širini/ožini naglašenih samoglasnikov $e$ in $o$ ter izgovarjavi fonemov $\dot{s}$ in $c$ ter $\dot{z}$ in $z$ (na primer v Miljah 'rẹca 'uho', 'pansia 'trebuh', $\dot{z} o$ ' $\gamma a$ tolo 'igrača', v Trstu 'recia, 'panca, zo'yatolo). ${ }^{2}$ Omenjene fonetične posebnosti smo zasledili tudi v krajih Bertoki in Hrvatini,3 kjer domačini romanskih korenin 4 govorijo različico beneščine, ki so jo oblikovali po vzoru tržaške italijanščine. Tukajšnji prebivalci so bili namreč v preteklosti močno povezani s Trstom; tu so pogosto našli zaposlitev in prodajali kmečke pridelke, saj si Koper z domačimi izdelki oskrbovali paolani - kmetje, ki so živeli v mestu, a so vsak hodili obdelovat zemljo na koprsko podeželje.

\section{METODOLOŠKI PRISTOP IN NAČIN PRIKAZOVANJA PODATKOV}

Gradivo za pripravo pričujočega prispevka smo pridobili med narečjeslovno raziskavo, ki smo jo opravili v Miljah v drugi polovici leta 2018 (prim. Todorović 2019b). Informante smo spodbujali k prostemu govorjenju o dogodkih, umeščenih v sedanjost, razširjeno sedanjost, preteklost, prihodnost in zunajčasovnost. Na osnovi pridobljenega korpusa smo prišli do nabora rab glagolskih časov, za katere smo skušali prepoznati osnovna pravila rabe. Pri interpretaciji slednjih smo se oprli na aktualno

1 Tudi to narečje uvrščamo v beneško narečno skupino.

2 Neobjavljeno gradivo, ki ga hrani avtorica monografije.

3 Oba kraja spadata v Mestno občino Koper.

$4 \quad$ V obeh krajih živijo tudi Istrani slovenskih korenin, ki govorijo rižansko podnarečje. 
italijansko slovnico (Dardano - Trifone 2013). Posnete pogovore in pripovedi smo transkribirali5 s slovenskimi in italijanskimi fonetičnimi znaki, ki smo jim dodali znake $\dot{s}$ - fonem med mehčanim in mehkim $\check{s}$ ('eser 'biti'), $\dot{z}$ - fonem med mehčanim in mehkim $\check{z}$ ('ku'żir 'šivati') in $\dot{c}$ - fonem med $\check{c}$ in $c$ ( $\dot{c} o r$ 'vzeti').

Narečni govorci, ki so sodelovali pri raziskavi, so bili:6

- Franco Stener, rojen 18. junija 1952

- Marco Stener, rojen 24. julija 1958

- Sergio Norbedo, rojen 31. avgusta 1955

- Lucilla Ugo, rojena 24. septembra 1938

- Francesco Russignan, rojen 18. junija 1940

\section{MILJSIKI GLAGOLSKI ČASI IN IZBRANE GLAGOLSKE OBLIKE}

Miljska istrobeneščina pozna, tako kot knjižna italijanščina, štiri glagolske naklone - povedni, vezalni, pogojni in velelni naklon (it. indicativo, congiuntivo, condizionale in imperativo) s sledečimi glagolskimi časi in glagolskimi oblikami: sedanjik, sedanjik konjunktiva, prihodnjik, sestavljeni prihodnjik, perfekt, perfekt konjunktiva, imperfekt, imperfekt konjunktiva, predpreteklik, predpreteklik konjunktiva, sedanji pogojnik, pretekli pogojnik, velelnik, gerundij, pretekli gerundij. Glagolski časi so lahko enostavni (na primer sedanjik - lavoro 'delam') ali sestavljeni, tj. tvorjeni iz spreganega pomožnega glagola in preteklega participa (na primer sestavljeni prihodnjik - avrò lavorato 'bom delal' itd.).

Pri prikazovanju miljskih glagolskih časov smo se oprli na sistem, ki smo ga uporabili za opis slovničnih posebnosti drugih istrskobeneških govorov, in sicer koprskega, izolskega, piranskega (prim. Todorović 2016: 193-253), hrvatinskega (Todorović 2017: 207-226) in bertoškega (Todorović 2018: 245-264) govora.

Pri opisu rabe enostavnih glagolskih časov smo v nadaljevanju navedli spregatve pomožnih glagolov biti in imeti, tj. 'eser in ya'ver, ter pravilnih glagolov z nedoločniškimi končnicami -ar, -er in -ir; pri razlagi sestavljenih glagolskih časov smo poleg rabe prikazali tudi njihovo tvorbo. Slednjo smo predstavili tudi za pretekli deležnik, velelnik, gerundij in pretekli gerundij. Za vse oblike smo zapisali več primerov iz narečja.

\subsection{Sedanjik}

S sedanjikom (it. presente indicativo) istrskobeneško govoreči Miljčani upovedujejo dejanja, aktualna v trenutku pripovedovanja, na primer Mi 'leğo el ğor'nal 'Berem časopis', in tista, ki se bodo zgodila v prihodnosti, na primer Do'man 'vado invru'mar $i$ 'kaki 'Jutri grem pobirat kakije'.

$5 \quad$ Zvočne posnetke hrani avtorica članka.

6 Od narečnih govorcev smo dobili dovoljenje za objavo podatkov. 
Omenjeni glagolski čas uporabljajo tudi za opisovanje preteklih dogodkov (historični sedanjik), na primer 'Ela la 'salta 'fọra 'dala fínestra, la 'vara ś $k^{\prime} w a l-$ ke'dun la 'vedi e la 'kori drijo'man 'vija 'Ona skoči skozi okno, pogleda, če jo kdo vidi, in takoj steče proč’, in za dejanja v zunajčasovnosti, kot v večnih resnicah, pregovorih, na primer 'La ma'dona kande'lora se la v'jen kol 'sol e 'bora de lin'verno 'semo 'fora, se la v'jen ko p'jova e 'vento de lin'verno 'semo 'dentro ... 'Če pride svečnica s soncem in burjo, zime ne bo več, če pa pride z dežjem in vetrom, smo še sredi zime'.

Pomožna glagola se spregata takole:

\begin{tabular}{|c|c|c|}
\hline osebni zaimek & 'eser 'biti' & ra'ver 'imeti' \\
\hline$m i$ & son & $\gamma o$ \\
\hline$t i t i$ & son & $\gamma a$ \\
\hline lu el & $\dot{z} e$ & $\gamma a$ \\
\hline éla la & $\dot{z} e$ & $\gamma a$ \\
\hline nu'altri $\mathbf{6 a}$ & '́semo & ra'vẹmo \\
\hline vu'altri $\mathbf{6 b}$ & $\dot{s} e$ & ra've \\
\hline 'lori $i$ & $\dot{z} e$ & $\gamma a$ \\
\hline lore le & $\dot{z} e$ & $\gamma a$ \\
\hline
\end{tabular}

\begin{tabular}{|c|c|c|c|}
\hline & $\begin{array}{c}-a r \\
\dot{s p e} \text { 'tar 'čakati' }\end{array}$ & 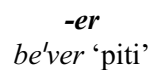 & $\begin{array}{c}-\boldsymbol{i r} \\
\text { dor'mir 'spati' }\end{array}$ \\
\hline$m i$ & $\dot{s}^{\prime}$ pẹto & 'bẹvo & 'dormo \\
\hline ti ti & $\dot{s}^{\prime} p e ̣ t i$ & 'bevi & 'dormi \\
\hline lu el & $\dot{s}^{\prime}$ pẹta & 'bevi & 'dormi \\
\hline éla la & $\dot{s}^{\prime} p e t a$ & 'bevi & 'dormi \\
\hline nu'altri & spe'tẹmo & be'vẹmo & dor'mimo \\
\hline vu'altri & spe'te & $b e^{\prime} v e$ & dor'mi \\
\hline 'lori $i$ & $\dot{s}^{\prime} p e ̣ t a$ & 'bevi & 'dormi \\
\hline lore le & $\dot{s}^{\prime} p e ̣ t a$ & 'bevi & 'dormi \\
\hline
\end{tabular}

Modalni glagoli in drugi glagoli, spregani v sedanjiku:

- $\quad \dot{s} a^{\prime} v e r$ 'vedeti, znati' (so, $\left.\dot{s} a, \dot{s} a, \dot{s} a^{\prime} v e m o, \dot{s} a^{\prime} v e, \dot{s} a\right)$

- voller 'želeti' ('vojo, 'vol, vol, vollemo, vo'le, 'vol)

- po'der 'moči' ('poso, 'pol, 'pol, po'dẹmo, po'de, 'pol)

- do'ver 'morati'('devo, 'devi, 'devi, do'vẹmo, do've, 'devi)

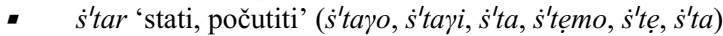

- on'dar 'iti' ('vado, 'vadi, 'va, on'demo, an'de, 'va)

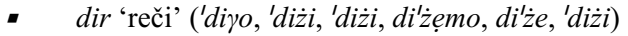

- $\quad \dot{c} o r$ 'vzeti' ('coyo, 'coli, '́col, co'lemo, colle, '́col)

6a Tudi $n u$ in noj'altri.

6b Tudi $v u$ in voj'altri. 


\subsection{Sedanjik konjunktiva}

Sedanjik konjunktiva nekateri istrskobeneški govorci uporabljajo za izražanje želje, dvoma, težnje, nestrinjanja, mnenja in podobno. Raba tega glagolskega časa je med Miljčani razmeroma redka, za istodobna dejanja v sedanjosti namreč večinoma uporabljajo običajni sedanjik.

Primeri: 'Mi no 'son si'kuro ke 'Elda la 'yabi (sedanjik konjunktiva) un la'vor, Mi no 'son si'kuro ke 'Elda la 'ya (sedanjik) un la'vor 'Nisem prepričan, da ima Elda službo'.

Pomožna glagola se spregata takole:

\begin{tabular}{|c|c|c|}
\hline & 'esier 'biti' & ya'ver 'imeti' \\
\hline$m i$ & 'sija & 'yabjo \\
\hline$t i t i$ & 'sija & ' $\gamma a b i$ \\
\hline lu el & 'sija & 'jabi \\
\hline éla la & 'sija & ' $\gamma a b i$ \\
\hline nu'altri & 'sẹmo & 'rabimo \\
\hline vu'altri & 'se & ya've \\
\hline lori $i$ & 'sija & 'yabi \\
\hline 'lore le & 'sija & 'jabi \\
\hline
\end{tabular}

\subsection{Prihodnjik}

Miljčani s prihodnjikom (it. futuro semplice) napovedujejo dejanja, ki se bodo uresničila v prihodnosti, na primer Do'man parla'ro 'kon k'wel fara'buto 'Jutri bom govoril s tisto barabo'

\begin{tabular}{|c|c|c|}
\hline & 'éser 'biti' & ra'ver 'imeti' \\
\hline$m i$ & $\dot{s} a^{\prime} r o$ & yava'ro \\
\hline$t i t i$ & $\dot{s} a^{\prime} r a$ & yava'ra \\
\hline lu el & $\dot{s} a^{\prime} r a$ & rava'ra \\
\hline éla la & $\dot{s} a^{\prime} r a$ & rava'ra \\
\hline nu'altri & $\dot{s} a^{\prime}$ rẹmo & yava'remo \\
\hline vu'altri & sa're & rava're \\
\hline lori $i$ & $\dot{s} a^{\prime} r a$ & rava'ra \\
\hline lore le & $\dot{s} a^{\prime} r a$ & java'ra \\
\hline
\end{tabular}




\begin{tabular}{|c|c|c|c|}
\hline & 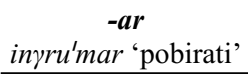 & 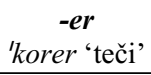 & 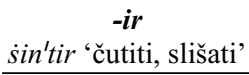 \\
\hline$m i$ & inүruma'ro & kore'ro & sinti'ro \\
\hline ti ti & in $\gamma r u m a^{\prime} r a$ & kore'ra & sinti'ra \\
\hline lu el & invruma'ra & kore'ra & sinti'ra \\
\hline éla la & bala'ra & kore'ra & sinti'ra \\
\hline nu'altri & inүruma'rẹmo & kore'rẹmo & sinti'rẹmo \\
\hline vu'altri & inyruma're & kore're & sinti're \\
\hline lori $i$ & inүruma'ra & kore'ra & sinti'ra \\
\hline lore le & invruma'ra & kore'ra & sinti'ra \\
\hline
\end{tabular}

\subsection{Sestavljeni prihodnjik}

Narečno govoreči iz Milj uporabljajo sestavljeni prihodnjik za prikazovanje zadobnih dejanj glede na neko napovedano dejanje, ki je izraženo s prihodnjikom, na primer Ko te veńa'ra in 'ćeża mi śa'ro 'ża 'la 'Ko boš prišel v cerkev, bom že tam'.

Ta glagolski čas je tvorjen z glagolom 'eser 'biti' ali $\mathrm{ya}^{\prime}$ ver 'imeti' v prihodnjiku in z ustrezno obliko preteklega deležnika.

\subsection{Perfekt}

S perfektom (it. passato prossimo) govorci narečja upovedujejo dejanja, ki so se zaključila v preteklosti. Tvorijo ga s pomožnim glagolom 'eser 'biti' ali ya'ver 'imeti' v sedanjiku in z ustrezno obliko preteklega deležnika.

Obrazila preteklih deležnikov iz glagolov s končnicami -ar, -er in -ir:

-ar ta'ka 'zlepil', spa'ra 'ustrelil', iүru'ma 'pobral', ser'ka 'iskal'

-er skri'vesto (sk'rito) 'napisal', vo'lesto (vo'lu) 'želel', do'vesto (do'vu) 'moral'

-ir vi'ńu 'prišel', for'bi 'počistil', mo'ri 'umrl'

Ob rabi pomožnega glagola 'esंer se obrazilo preteklega deležnika prilagaja glede na spol in število, na primer mi son par'tido 'odpotoval sem', mi son par'tida 'odpotovala sem', 'lori $i$ że par'tij 'odpotovali so', 'lore le że par'tide 'odpotovale so'; če glagol zahteva rabo pomožnega glagola ya'ver, se obrazilo preteklega deležnika ne spreminja, na primer el ya ba'la 'plesal je', 'lori i ya ba'la 'plesali so'.

Navedeno pravilo velja za vse analitično tvorjene glagolske čase, tj. tvorjene $\mathrm{z}$ glagolom biti ali imeti in preteklim deležnikom (sestavljeni prihodnjik, perfekt, perfekt konjunktiva, predpreteklik, predpreteklik konjunktiva, pretekli pogojnik, pretekli gerundij) (Todorović 2018: 257).

Primeri: Гo 'perso 'meża jor'nada 'par 'far 'sta 'roba 'Izgubil sem pol dneva, da bi naredil to stvar', Ti ya pron'ta la 'tola, ke że 'ora de ma'ńar ... 'Si pripravil (pripravila) mizo; čas je za obedovanje ...', La ya 'meśo na blu'żeta 'nova, ke ye s'tava p'ropjo ben 'Oblekla si je bluzico, ki ji je prav pristajala', Ti ra 'onto 'ben la far'sora, p'rima de 'meterla sul 'foyo? 'Si dobro naoljil (naoljila) ponev, preden si 
jo dala na ogenj?', 'El se ya ma'ća 'duto el vis'tito 'Umazal si je vso obleko', 'Par el karne'val la ya ku'żi un 'mućo de viś'titi 'Za pusta je zašila veliko oblek'.

\subsection{Perfekt konjunktiva}

Perfekt konjunktiva govorci obravnavanega narečja uporabljajo razmeroma redko. Tvorjen je s sedanjikom konjunktiva pomožnih glagolov 'eser ali ya'ver in preteklim deležnikom, na primer 'Ela la k'redi ke 'el 'sija an'da 'vija 'Ona misli, da je odšel proč'.

Analiza pridobljenega korpusa je pokazala, da govorci omenjeni glagolski čas nadomeščajo z običajnim perfektom, na primer 'Ela la k'redi ke 'el że an'da 'vija.

\subsection{Imperfekt}

$\mathrm{Z}$ imperfektom (it. imperfetto) narečni govorci upovedujejo istodobna dejanja glede na neki pretekli dogodek, pretekla stanja, ponavljajoče se pretekle dogodke, trajajoča dejanja v preteklosti ter nerealne hipotetične dogodke.

\begin{tabular}{|c|c|c|}
\hline & 'eser 'biti' & $\gamma a^{\prime}$ ver 'imeti' \\
\hline$m i$ & 'jero & 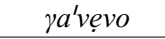 \\
\hline$t i t i$ & 'jeri & ra'vevi \\
\hline lu el & jera & ra'vẹa \\
\hline éla la & jera & $\gamma a^{\prime} v e v a$ \\
\hline nu'altri & 'jerimo & ra'vẹvimo \\
\hline vu'altri & 'jeri & $\gamma a^{\prime} v e v i$ \\
\hline lori $i$ & jera & 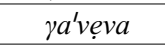 \\
\hline 'lore le & jera & 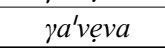 \\
\hline
\end{tabular}

\begin{tabular}{|c|c|c|c|}
\hline & $\begin{array}{c}-a r \\
s i i^{\prime} \gamma a r \text { 'kričati' }\end{array}$ & 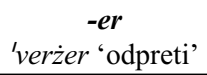 & 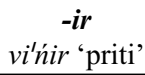 \\
\hline$m i$ & $\dot{s i} i^{\prime}$ Yavo & le '̌gevo & vi'ńivo \\
\hline$t i t i$ & $\dot{s i} i^{\prime} \gamma a v i$ & le'ğevi & vi'ńivi \\
\hline lu el & $\dot{s i} i^{\prime} \gamma a v a$ & le'ğeva & vilniva \\
\hline éla la & $\dot{s i} i^{\prime}$ Yva & le'ǧeva & vi'ńiva \\
\hline nu'altri & 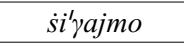 & le'ğejmo & vi'ńivimo \\
\hline vu'altri & $\dot{s i} i^{\prime} \gamma a v i$ & le'ğevi & $v i^{\prime} n \dot{n} i v i$ \\
\hline lori $i$ & $\dot{s i} i^{\prime} \gamma a v a$ & le'ğeva & vi'ńiva \\
\hline 'lore le & $\dot{s} i^{\prime} \gamma a v a$ & le ǧgeva & vi'ńiva \\
\hline
\end{tabular}

Primeri: Гe 'jera na 'lama de 'akwa e el mu'leto 'jera 'duto kon'tento, 'bateva $i$ 'pije ke 'jera ne'ga 'fin 'sora $i$ ka'vej 'Tam je bila luža in deček je bil ves vesel, teptal je z nogami, da je bil moker od glave do pete', El stri'kava ke no lo żvejava ni'anka

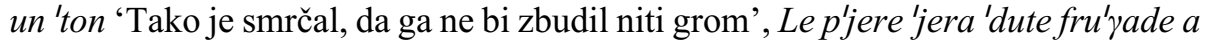
'forsia de rra'tarle kon la śkar'tasia, 'akwa e śa'von 'Kamni so bili obrabljeni zaradi drgnjenja s krtačo, vodo in milom', 'Jera un 'mućo de 'tole in 'parte la'sade daj 
mura'dori 'Ob strani je bilo veliko ploščic, ki so jih pustili zidarji', El ya'veva in

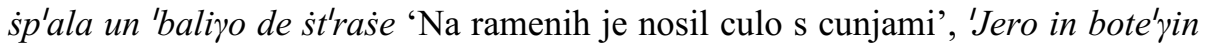
'dela vende'riyola kwa in 'kale d'rijo el kan'ton e yo 'visto ko la 'koda del 'oćo ke el mu'leto ye ya be'ka do sar'jeże 'Bil sem v trgovini s sadjem in zelenjavo tukaj takoj za vogalom in sem videl mulca, ki ji je vzel dve češnji’.

$\mathrm{Z}$ imperfektom (indikativa) ${ }^{7}$ lahko govorci predstavijo tudi pretekle hipotetične dogodke, za upovedovanje katerih italijanska slovnica narekuje strogo rabo (predpreteklika) konjunktiva in (preteklega) pogojnika, na primer knjižno italijansko Se ci avessero invitato ci saremmo andati volentieri, miljsko istrskobeneško $\dot{S}$ e $i$ ne invi'tava, an'davimo volent'jeri 'Če bi nas povabili, bi šli rade volje’.

\subsection{Imperfekt konjunktiva}

Govorci uporabljajo imperfekt konjunktiva (it. congiuntivo imperfetto) predvsem v odvisnih stavkih, če je v glavnem stavku (v sedanjiku, pretekliku ali imperfektu) izražen dvom, želja težnja in podobno, na primer No k'redo ke el po'desi aju'tarlo 'Ne verjamem, da bi mu lahko pomagal', Ma'rija la kre'deva ke Lu'iża le fáseśe $k^{\prime}$ westo pja'ser 'Marija je verjela, da ji bo Luisa naredila to uslugo'.

Imperfekt konjunktiva zasledimo tudi v enostavčnih povedih, ki izražajo željo, na primer Ma'jari 'Marjo ve'nissi a 'ćorme! 'Ko bi Marjo le prišel pome!'.

Rabo omenjenega glagolskega časa smo zasledili tudi v pogojnih povedih, $\mathrm{v}$ tako imenovanem realnem ali možnem hipotetičnem dogodku. Za tovrstna upovedovanja italijanska slovnica narekuje rabo sedanjega pogojnika v glavnem stavku in imperfekta konjunktiva v odvisniku, na primer Se avessimo tempo, andremmo con loro, miljsko istrskobeneško Ś ya'vesimo 'tenpo, anda'rijimo ko 'lori 'Če bi imeli čas, bi šli z njimi'.

Možni hipotetični dogodek narečni govorci lahko upovejo po vzoru knjižne italijanščine ali s poljubno rabo imperfekta konjunktiva in sedanjega pogojnika tako v glavnem kot v odvisnem stavku, na primer $\dot{S}$ e 'ela la vi'ńisi a lavo'rar in peśke'rija, ne aiute'rija 'śaj (imperfekt konjunktiva, sedanji pogojnik), Śe 'ela la ven'rija a lavo'rar in peske'rija, ne aju'tasi 'śaj (sedanji pogojnik, imperfekt konjunktiva), Śe 'ela la vi'ńisi a lavo'rar in peśke'rija, ne aju'tasi 'śaj (imperfekt konjunktiva, imperfekt konjunktiva), Śe 'ela la vene'rija a lavo'rar in peśke'rija, ne ajute'rija 'śaj (sedanji pogojnik, sedanji pogojnik) 'Če bi prišla delat v ribarnico, bi nam zelo pomagala'.

7 Raba imperfekta za signaliziranje preteklega hipotetičnega dogodka je značilna tudi za italijanski pogovorni jezik, na primer Se lo sapevo, te lo dicevo 'Če bi vedel, bi ti povedal', knjižno italijansko Se lo avessi saputo, te lo avrei detto. 


\begin{tabular}{|c|c|c|}
\hline & 'eser 'biti' & ya'ver 'imeti' \\
\hline$m i$ & 'fosi $i$ & $\gamma a^{\prime} v e \dot{s} i$ \\
\hline$t i t i$ & 'fosi & $\gamma a^{\prime}$ vesi $i$ \\
\hline lu el & fosi & ra'vesi $i$ \\
\hline 'ela la & 'fosi & $\gamma a^{\prime}$ vesi $i$ \\
\hline nu'altri & 'fosimo & ra'vesimo \\
\hline vu'altri & 'fosi & $\gamma a^{\prime} v e \dot{s i}$ \\
\hline lori $i$ & 'fosi $i$ & $\gamma a^{\prime}$ vesi $i$ \\
\hline 'lore le & 'fosi & $\gamma a^{\prime} v e \dot{s} i$ \\
\hline
\end{tabular}

\begin{tabular}{|c|c|c|c|}
\hline & $\begin{array}{c}-\boldsymbol{a r} \\
\dot{s} k a n^{\prime} p a r \text { 'bežati' }\end{array}$ & $\begin{array}{c}\text {-er } \\
\dot{z}^{\prime} m e t e r \text { 'nehati' }\end{array}$ & $k u^{\prime} \dot{z} i r$ 'šivati' \\
\hline$\overline{m i}$ & $\dot{s k a n}{ }^{\prime} p a \dot{s} i$ & $\dot{z} m e^{\prime} t e ̣ s i$ & $k u^{\prime} \dot{z} i \dot{s} i$ \\
\hline$t i t i$ & $\dot{s} k a n^{\prime} p a \dot{s} i$ & $\dot{z} m e^{\prime} t e ̣ \dot{s} i$ & $k u^{\prime} \dot{z} i \dot{s} i$ \\
\hline lu el & $\dot{s} k a n^{\prime} p a \dot{s} i$ & $\dot{z} m e^{\prime} t e \dot{s} i$ & $k u^{\prime} \dot{z} i \dot{s} i$ \\
\hline éla la & skan'pasi & $\dot{z} m e^{\prime} t e ̣ \dot{s} i$ & $k u^{\prime} \dot{z} i \dot{s} i$ \\
\hline$n u^{\prime} a l t r i$ & śkan'pasimo & żme'tẹsimo & ku'żisimo \\
\hline vu'altri & $\dot{s} k a n^{\prime} p a \dot{s} i$ & $\dot{z} m e^{\prime} t e ̣ \dot{s} i$ & $k u^{\prime} \dot{z} i \dot{s} i$ \\
\hline 'lori $i$ & $\dot{s} k a n^{\prime} p a \dot{s i}$ & $\dot{z} m e^{\prime} t e \dot{s} i$ & $k u^{\prime} \dot{z} i \dot{s} i$ \\
\hline 'lore le & $\dot{s k a n ' p a s i}$ & $\dot{z} m e^{\prime} t e \dot{s} i$ & $k u^{\prime} \dot{z} i \dot{s} i$ \\
\hline
\end{tabular}

\subsection{Predpreteklik}

Predpreteklik govorci uporabljajo, ko orisujejo preddobna dejanja glede na nek ipretekli dogodek, ki je upoveden z imperfektom ali perfektom, na primer Ma'rija ya konp'ra du'te le 'robe par la 'każa koj 'bori ke ye ya'veva man'da su so'rela ke vi'veva in Ame'rika 'Marija je kupila vse stvari za hišo z denarjem, ki ji ga je poslala njena sestra, ki je živela v Ameriki'.

Primeri: 'jerano tor'naj 'so (bili) prišli', ya'veva edu'ka 'je (bil) vzgojil', 'jerano par'tide, 'so (bile) odpotovale', yo kape'la 'sem se (bil) zmotil' in drugo.

\subsection{Predpreteklik konjunktiva}

Predpreteklik konjunktiva Miljčani uporabljajo za upovedovanje preddobnih dejanj glede na neka pretekla dejanja, izražena z imperfektom ali perfektom, a mora glavni stavek izražati dvom, željo, težnjo, nestrinjanje in podobno, na primer $M e$ pa'reva ke ti ya'vessi fi'ka el 'pije intel p'loc p'jen de 'akwa 'Zdelo se mi je, da si vtaknil nogo v lužo, polno vode'.

Predpreteklik konjunktiva je tvorjen s pomožnim glagolom 'eser 'biti' ali $\gamma a^{\prime}$ 'ver 'imeti' v imperfektu konjunktiva in ustrezno obliko preteklega deležnika, na primer $\gamma a v e$ 'si sia'vesto 'si/sem/je vedel / bi vedel', 'fusi an'da 'si/sem/je šel / bi šel'.

$\mathrm{S}$ tem glagolskim časom in s preteklim pogojnikom, na primer Se no la 'fusi $\dot{s}^{\prime} t a d a$ 'śensia eduka'sjon, lu non se śa'rija rab'ja 'Č e ne bi bila neolikana, se on ne bi razjezil', govorci opisujejo nerealni hipotetični dogodek. Tudi v tem primeru lahko poljubno uporabijo konjunktiv in pogojnik, na primer Śe no la 'fusis s'tada 


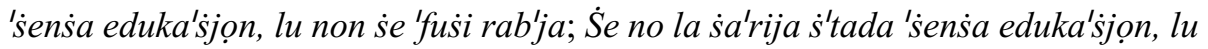
non se śa'rija rab'ja.

\subsection{Sedanji pogojnik}

Miljski sedanji pogojnik narečni govorci uporabljajo, da bi izrazili svojo željo, namero, nasvet, mnenje in podobno, na primer Mi di'rija ke fa'ra bel 'tenpo 'Rekel bi, da bo lepo vreme', Śa'rija 'justo 'dirye 'duto a Lu'iża 'Prav bi bilo, da bi povedali Luisi', Vola'rija par'tir ma no yo ni'sun ke me kon'pańi 'Rada bi odpotovala, a nimam nikogar, ki bi me spremljal'.

Pogosto ga nadomeščajo $\mathrm{z}$ imperfektom konjunktiva, in sicer tudi v primerih, v katerih italijanska slovnica zapoveduje rabo sedanjega pogojnika, na primer Come pittureresti questa camera?, miljsko istrskobeneško 'Kome ti pitu'rasis sta 'kamera? 'Kako bi ti pobelil to sobo?'.

Izpostavili smo že, da govorci s sedanjim pogojnikom in imperfektom opisujejo realni hipotetični dogodek in da ju lahko uporabljajo poljubno, v glavnem in/ ali odvisnem stavku.

\begin{tabular}{|c|c|c|}
\hline & 'éser 'biti' & ya'ver 'imeti' \\
\hline$m i$ & $\dot{s} a^{\prime} r i j a$ & yava'rija \\
\hline$t i t i$ & $\dot{s} a^{\prime} r i j a$ & rava'rija \\
\hline lu el & $\dot{s} a^{\prime} r i j a$ & rava'rija \\
\hline éla la & $\dot{s} a^{\prime}$ rija & rava'rija \\
\hline nu'altri & $\dot{s} a^{\prime}$ rijimo & 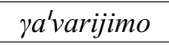 \\
\hline vu'altri & $\dot{s} a^{\prime} r i j i$ & yava'riji \\
\hline lori $i$ & $\dot{s} a^{\prime} r i j a$ & rava'rija \\
\hline lore le & $\dot{s} a^{\prime} r i j a$ & rava'rija \\
\hline
\end{tabular}

\begin{tabular}{|c|c|c|c|}
\hline & $\begin{array}{c}\text {-ar } \\
\text { kape'lar 'zmotiti se' }\end{array}$ & 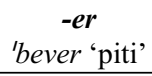 & $\begin{array}{c}-i r \\
\text { brusto'lir 'pražiti' }\end{array}$ \\
\hline$m i$ & kapela'rija & beve'rija & brustoli'rija \\
\hline$\overline{t i t i}$ & kapela'rija & beve'rija & brustoli'rija \\
\hline lu el & kapela'rija & beve'rija & brustoli'rija \\
\hline éla la & kapela'rija & beve'rija & brustoli'rija \\
\hline nu'altri & kapela'rijimo & beve'rijimo & brusitoli'rijimo \\
\hline vu'altri & kapela'rija & beve'riji & bruśtoli'riji \\
\hline 'lori $i$ & kapela'rija & beve'rija & brustoli'rija \\
\hline lore le & kapela'rija & beve'rija & brustoli'rija \\
\hline
\end{tabular}

\subsection{Pretekli pogojnik}

Pretekli pogojnik uporabljajo, ko opisujejo zadobna dejanja glede na neko preteklo dejanje, ki je opisano z imperfektom ali perfektom, na primer 'Elda ne ya 'dito ke śa'rija an'dada a Tri'jeste de su mo'rożo 'Elda nam je povedala, da bo šla k zaročencu v Trst'. 
Pretekli pogojnik je sestavljen iz pomožnega glagola 'eser 'biti' ali ya'ver 'imeti' v pogojniku in iz ustrezne oblike preteklega deležnika, na primer $\dot{s} a$ 'rija on'dada 'bo šla', ra'varija vu 'bom/boš/bo imel'.

S tem glagolskim časom govorci lahko opisujejo nerealne hipotetične dogodke, in sicer s poljubno izbiro preteklega pogojnika in predpreteklega konjunktiva v glavnem in/ali odvisnem stavku.

\subsection{Velelnik}

V preglednicah prilagamo velelniške (it. imperativo) oblike za drugo osebo ednine in množine pomožnih glagolov 'éser 'biti' in $\gamma a^{\prime}$ ver 'imeti' ter za pravilne glagole na -ar (na primer śkan'par 'zbežati'), -er (na primer $\dot{z}^{\prime} m e ̣ t e r$ 'nehati') in -ir (na primer $k u^{\prime}$ żir 'šivati').

\begin{tabular}{|c|c|c|}
\hline & 'éser 'biti' & ya'ver 'imeti' \\
\hline$t i t i$ & ' $\dot{s} i$ & ' $\gamma a b i$ \\
\hline vu'altri & 'se & ra've \\
\hline
\end{tabular}

\begin{tabular}{|c|c|c|c|}
\hline & $-a r$ & $-e r$ & $-i r$ \\
\hline$t i t i$ & $\dot{s}^{\prime}$ kanpa & $\dot{z}^{\prime} m e t i$ & 'kużi \\
\hline$v u^{\prime}$ altri & skan'pe & żme'te & $k u^{\prime} z i$ \\
\hline
\end{tabular}

Primeri: In $\gamma^{\prime} r u m a ~ k ' w e l e ~ s ́ k o ' v a \dot{s e}$ 'Poberi tiste smeti', 'Tasime un fja de pre'sẹmo-

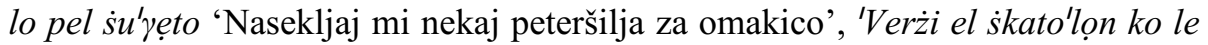
bo'tile de vin 'Odpri škatlo s steklenicami vina'.

\subsection{Sedanji in pretekli gerundij}

Miljski narečno govoreči uporabljajo tudi sedanji in pretekli gerundij. V preglednicah prilagamo oblike pomožnih glagolov 'eser 'biti' in $\gamma a^{\prime}$ ver ter pravilnih glagolov na - $\operatorname{ar}$ (na primer inүru'mando 'pobirajoč'), -er (na primer be'vendo 'pijoč') in -ir (dor'mindo 'speč').

\begin{tabular}{|c|c|c|}
\hline 'eser 'biti' & $\gamma a^{\prime}$ ver 'imeti' & \\
\hline 'sendo & $\gamma a^{\prime}$ vendo & \\
\hline$-a r$ & $-e r$ & $-i r$ \\
\hline inyru'mando & be'vẹndo & dor'mindo \\
\hline
\end{tabular}

Primeri: El 'dindjo kami'nava fra le 'vide fa'sendo la 'roda e ser'kando de 'bakar l'uva 'Puran je hodil med trtami tako, da je vozil kočijo in poskušal kljuvati grozde', Ma'ńando ku'si te diventa'ra na ba'lena 'Če boš tako (toliko) jedel/jedla, boš postal/postala kit'. 
Pretekli gerundij je tvorjen s pomožnim glagolom 'éser 'biti' ali $\gamma a^{\prime}$ ver 'imeti' v sedanjem gerundiju in s preteklim deležnikom, na primer Śn'do par'tidi de bon'ora no ya'vemo pod'ẹsto salu'tar ni'sun 'Ker smo odpotovali zgodaj, nismo utegnili pozdraviti nikogar'.

\section{SKLEP}

Milje so istrsko mestece, v katerem domačini govorijo istrskobeneško narečje, ki sodi v beneško narečno skupino, natančneje v skupino kolonialnih beneških govorov. V članku Osnovna slovnica miljskega istrskobeneškega govora: od fonemskega sestava do zaimkov (Todorović 2019b) smo predstavili miljske foneme in nekatere oblikoslovne posebnosti, v pričujočem prispevku pa smo prikazali glagolske čase in izbrane glagolske oblike. Narečjeslovne podatke smo dobili med raziskavo, ki smo jo opravili v letu 2018.

Miljska istrobeneščina pozna štiri glagolske naklone in več glagolskih časov ter glagolskih oblik - sedanjik, sedanjik konjunktiva, prihodnjik, sestavljeni prihodnjik, perfekt, perfekt konjunktiva, imperfekt, imperfekt konjunktiva, predpreteklik, predpreteklik konjunktiva, sedanji pogojnik, pretekli pogojnik, velelnik, gerundij, pretekli gerundij.

Iz pridobljenega narečnega korpusa smo razbrali načine in pravila upovedovanja aktualnih, preteklih, prihodnjih in zunajčasovnih dogodkov ter preddobnih, zadobnih in istodobnih dejanj glede na neko osrednje dejanje.

Za vse glagolske čase in izbrane glagolske oblike smo določili spregatve pomožnih glagolov 'eser 'biti', ya'ver 'imeti' in pravilnih glagolov z nedoločniškimi končnicami - $a r$, -er in -ir; pri razlagi sestavljenih glagolskih časov smo poleg rabe prikazali tudi njihovo tvorbo. Vse razlage smo opremili z več primeri iz narečja.

Raziskava je pokazala, da so istrskobeneški načini upovedovanja podobni tistim, ki jih pozna knjižna italijanščina, izvzemši rabo vezalnega naklona. Narečni govorci razmeroma redko uporabljajo sedanjik konjunktiva in perfekt konjunktiva, imperfekt konjunktiva in predpreteklik konjunktiva pa pogosto nadomeščajo $\mathrm{s}$ sedanjim in preteklim pogojnikom, predvsem pri tako imenovanem hipotetičnem dogodku, kjer - v popolnem nasprotju z italijansko slovnico - poljubno izbirajo konjunktiv in pogojnik tako v glavnem kot (tudi) odvisnem stavku. 


\section{VIRI IN LITERATURA}

Dardano - Trifone 2013 = Maurizio Dardano - Pietro Trifone, Grammatica italiana con nozioni di linguistica, Bologna: Zanichelli, 2013.

Filipi 1993 = Goran Filipi, Istriotski jezikovni otoki v Istri, Annales: series historia et sociologia 11 (1993), 275-284.

Folena 1968-1970 = Gianfranco Folena, Introduzione al veneziano »de là da mar«, Bollettino dell'Atlante linguistico mediterraneo, 10-12 (1968-1970), 331-376.

Todorović $\mathbf{2 0 1 6}$ = Suzana Todorović, Narečje v Kopru, Izoli in Piranu, Koper: Libris, 2016.

Todorović 2017 = Suzana Todorović, Narečna raznolikost v okolici Kopra, Koper: Libris, 2017.

Todorović 2018 = Suzana Todorović, Raznovrstnost narečnih govorov na Koprskem, Koper: Libris, 2018.

Todorović 2019a = Suzana Todorović, Istrobeneščina v krogu drugih jezikov in govorov v slovenskih obmorskih krajih, Koper: Libris, 2019.

Todorović 2019b = Suzana Todorović, Osnovna slovnica miljskega istrskobeneškega govora: od fonemskega sestava do zaimkov, Jezikoslovni zapiski 25.2 (2019), 97-111.

Zamboni 1979 = Alberto Zamboni, Le caratteristiche essenziali dei dialetti veneti: guida ai dialetti veneti, ur. Manlio Cortelazzo, Padova: Cleup, 1979.

\section{SUMMARY}

\section{A Short Grammar of the Muggia Vernacular: Verb Tenses and Selected Verb Forms}

This article presents the verb forms that speakers of the Muggia Istrian-Venetian dialect use in everyday communication. The material for presenting this segment of the Muggia dialect grammar was obtained through a dialectological study conducted in 2018. Presented are the conjugations of the auxiliary verbs 'eser 'be' and $\gamma a^{\prime}$ ver 'have' for individual forms of verbalization and the conjugation patterns for regular verbs ending in -ar, -er, and $-i r$. The rules for using the Muggia dialect verb forms are similar to those dictated by Italian grammar, except for the subjunctive and conditional, especially in relation to hypothetical events.

The study showed that the Istria-Venetian forms of verbalization are similar to those in standard Italian, except for the use of the subjunctive. Dialect speakers use the present and the perfect subjunctive relatively rarely, and they often replace the imperfect and past perfect subjunctive with the present and past conditional, especially for hypothetical events. 